\title{
The role of MTHFR C677T and ALDH2 Glu504Lys polymorphism in acute coronary syndrome in a Hakka population in southern China
}

Jingyuan Hou ${ }^{1,2,3^{*}}$, Zhixiong Zhong ${ }^{2,3,4}$, Qiaoting Deng ${ }^{1,2,3}$, Lifang Lin ${ }^{1,2,3}$ and Xing Zeng ${ }^{1,2,3}$

\begin{abstract}
Background: Acute coronary syndrome (ACS) is the most serious type of coronary heart disease and is a global medical burden. The pathogenesis of ACS is very complex and still poorly understood. Epidemiologic studies have revealed that the manifestation of ACS are the results of the interactions between multiple environmental and genetic factors. The present study aimed to investigate the role of polymorphisms of MTHFR C677T and ALDH2 Glu504Lys as risk factors for ACS in a Hakka population in southern China.

Methods: Between September 1, 2015 and October 31, 2017, a total of 1957 individuals, including 860 ACS patients and 1097 controls were recruited. Blood samples were collected and genotypes were determined by DNA microarray chip method and direct sequencing method.

Results: For the MTHFR C677T polymorphism, frequencies of CC, CT, and $\pi$ genotypes were $53.60 \%$ versus 55.33 , $39.53 \%$ versus 38.65 and $6.86 \%$ versus $6.02 \%$ in patients with ACS versus controls, respectively $(p>0.05)$. The differences in genotype frequencies between the ACS patients and controls in the three genetic model were not statistically significant. For the ALDH2 Glu504Lys polymorphism, the frequencies of $A L D H 2^{*}{ }^{*} 1, A L D H 2^{*} 1^{*} 2$, and $A L D H 2 * 2 * 2$ genotypes were $48.72,42.67$ and $8.6 \%$ in the ACS patients, respectively, while these were $53.33,39.11$ and $7.57 \%$ in the controls, respectively, showing no significant difference in the distribution of the ALDH2 genotype between the groups. Using the wild genotype $\mathrm{ALDH}_{2}^{*}{ }^{*} 1$ as reference, relative risk analysis revealed a slightly increased risk for ACS in individuals with the $A L D H 2^{*} 1^{*} 2$ plus $A L D H 2 * 2 * 2$ genotypes (odds ratio $(O R)=1.203,95 \%$ confidence interval $(C \mathrm{C})=1.006-1.438, p=0.043)$. In a multivariate logistic regression model, even after adjusting for potential covariates, the association between $A L D H 2 * 2$ allele and $A C S$ remained significant $(O R=1.242,95 \% \mathrm{Cl}=$ $1.045-1.561, p=0.038)$.

(Continued on next page)
\end{abstract}

\footnotetext{
* Correspondence: monkeyhjy@126.com

'Clinical Core Laboratory, Meizhou People's Hospital (Huangtang Hospital),

Meizhou Hospital Affiliated to Sun Yat-sen University, No. 63 Huangtang

Road, Meijiang District, Meizhou 514031, People's Republic of China

${ }^{2}$ Guangdong Provincial Key Laboratory of Precision Medicine and Clinical

Translational Research of Hakka Population, Meizhou 514031, People's

Republic of China

Full list of author information is available at the end of the article
}

(C) The Author(s). 2020 Open Access This article is licensed under a Creative Commons Attribution 4.0 International License, which permits use, sharing, adaptation, distribution and reproduction in any medium or format, as long as you give appropriate credit to the original author(s) and the source, provide a link to the Creative Commons licence, and indicate if changes were made. The images or other third party material in this article are included in the article's Creative Commons licence, unless indicated otherwise in a credit line to the material. If material is not included in the article's Creative Commons licence and your intended use is not permitted by statutory regulation or exceeds the permitted use, you will need to obtain permission directly from the copyright holder. To view a copy of this licence, visit http://creativecommons.org/licenses/by/4.0/ The Creative Commons Public Domain Dedication waiver (http://creativecommons.org/publicdomain/zero/1.0/) applies to the data made available in this article, unless otherwise stated in a credit line to the data. 


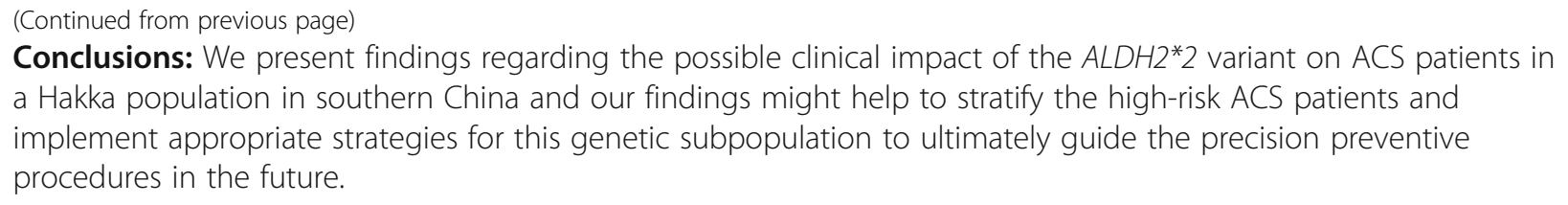

Keywords: Acute coronary syndrome, Methylenetetrahydrofolate reductase, Aldehyde dehydrogenase 2, Gene polymorphism, Hakka

\section{Background}

Acute coronary syndrome (ACS) is the most serious type of coronary heart disease and is a global medical burden [1]. ACS refers to a broad spectrum of clinically manifest coronary artery disease compatible with unstable angina and myocardial infarction (MI) with or without ST elevation [2-4]. Indeed, the pathophysiology, clinical presentation and prognosis of ACS are extremely heterogeneous $[5,6]$. Patients identified as high-risk groups may be undertook earlier health management and more aggressive treatment, and thus early identifying individual at risk of ACS is of paramount importance [7, 8]. ACS is a complex disorder that involves multiple environmental and genetic factors. It has been generally reported that lifestyle such as low physical activity, obesity, smoking, drinking and fast food intake are found to be associated with patients with ACS [9-11]. However, since the traditional environment and lifestyle factors reflects only a small part of mechanisms related to the development of ACS, whereas the relationship between genetic molecular mechanisms and future ACS, was not addressed [12, 13].

Methylenetetrahydro folate reductase (MTHFR) plays a significant role in cellular metabolism of folate, as well as in the synthesis of purine, DNA, and RNA and is essential in the methyl cycle that converts homocysteine (Hcy) to methionine $[14,15]$. MTHFR is a crucial controlling enzyme related to Hcy metabolism and many articles connecting MTHFR single nucleotide polymorphism (SNP), mostly MTHFR C677T, with plasma Hcy levels [16]. There are growing evidences that elevated plasma Hcy concentration confers an increased risk for cerebrovascular, peripheral vascular disease and the occurrence of cardiovascular disease in patients with or without hypertension, diabetes mellitus and other conventional risk factors [17-19]. However, to date, most studies of MTHFR C677T polymorphism on ACS are not fully understood.

Mitochondrial aldehyde dehydrogenase 2 (ALDH2) has been proved to responsible for oxidation and detoxification of aromatic and aliphatic aldehydes [20]. The significant functional polymorphism of the $A L D H 2$ gene is at exon 12, wherein glutamate acid (Glu) is replaced by lysine (Lys) at position 504(Glu504Lys) [21]. Carriers of the variant $A L D H 2$ allele $(A L D H 2 * 2)$ have dramatically deficient enzymatic activity by approximately 60 to $80 \%$ in heterozygotes and found in approximately 560 million people of East Asian descent but are virtually nonexistent in other populations of the world [22, 23]. Numerous studies suggest that variations of $A L D H 2$ are associated with the risk for a series of diseases such as alcoholic cirrhosis, cancer, Alzheimer's and stroke [2426]. Moreover, the reduced activity of the mitochondrial ALDH2 causes accumulation of acetaldehyde and 4hydroxy-2-nonenal (4-HNE) and decrease the anti-oxidative stress effects, which has been proposed to be potentially linked with coronary artery disease (CAD) [27-29].

To the best of our knowledge, there is currently no report that evaluated the role of polymorphisms of MTHFR C677T and ALDH2 Glu504Lys in ACS patients in a Hakka population in southern China. We hypothesized that polymorphisms of the $A L D H 2$ and MTHFR gene that result in reduced enzyme activity may modify the risk of ACS. We tested this hypothesis in a case-control study.

\section{Methods \\ Study population}

This was a retrospective study that analyzed consecutive patients who visited the cardiovascular medicine of our hospital, which is a tertiary hospital located in urban area between September 1, 2015 and October 31, 2017. The annual patients admitted to the cardiovascular medicine were ranged from 10,000 to 12,000 patients. Participants of this study include native inhabitants in Meizhou region for at least 3 generations with no migration history, from both rural and urban origins. A total of 1957 individuals, including 860 ACS patients and 1097 controls were recruited. ACS patients were diagnosed by two senior specialists at the time of the index hospitalisation according to the same clinical criteria defined by the European Society of Cardiology/American College of Cardiology. Control subjects were free of cardiac disorders according to medical history, physical and laboratory examinations. The present study complies with the Declaration of Helsinki and was approved by the ethics committee of the Meizhou People's Hospital (Huangtang Hospital), Meizhou Hospital Affiliated to Sun Yat-sen University. A prior written informed consent was obtained from patients and controls who participated in the present study before inclusion. 


\section{Definitions}

The ACS was classified as ST segment elevation myocardial infarction (STEMI), non-ST segment elevation myocardial infarction (NSTEMI) and unstable angina pectoris (UA) based on clinical, electrocardiographic, and biochemical criteria. In brief, STEMI was defined as presence of persistent chest pain along with at least one of the following: new-onset ST segment elevation $\geq 1 \mathrm{~mm}$ in at least 2 contiguous leads in the admission electrocardiogram, or left bundle branch block and elevated cardiac biomarker values above the upper limit of normal range. NSTEMI was defined as presence of persistent chest pain, absence of new-onset ST segment elevation, and/or the presence of $\mathrm{T}$-wave abnormalities and elevated cardiac biomarker above the upper limit of normal range. UA was defined as worsening angina without elevated values of cardiac biomarker. Patients were excluded if they had a previous history of ACS, percutaneous coronary intervention or coronary artery bypass graft surgery, malignant tumor, blood system diseases, autoimmune diseases and severe hepatic or renal dysfunction.

Information on the age, gender, smoker, and drinker, hypertension, diabetes and dyslipidemia were collected from the medical records. Smoker was defined as those daily smoking for more than 5 cigarettes. Drinker was defined as a person who drinks hard liquors at least once per week and continuously drinks for more than a year. Hypertension was defined as history of hypertension or systolic blood pressure $(\mathrm{SBP}) \geq 140 \mathrm{mmHg}$ or diastolic $\mathrm{BP}(\mathrm{DBP}) \geq 90 \mathrm{mmHg}$. Diabetes was defined as history of diabetes or a fasting plasma glucose level of $\geq 7.0 \mathrm{mmol} /$ $\mathrm{L}$ or 2 -h OGTT venous blood glucose level $\geq 11.1 \mathrm{mmol} /$ $\mathrm{L}$ and a hemoglobin A1c level of $\geq 6.5 \%$. Dyslipidemia was defined as level of triglycerides (TG) value of $\geq 1.50$ $\mathrm{mmol} / \mathrm{L}$ or $\mathrm{LDL}$ cholesterol (LDL-c) value of $\geq 3.92$ $\mathrm{mmol} / \mathrm{L}$ or under medication of lipid lowering drugs.

\section{Blood sampling and genotyping}

Five millilitres of venous blood was collected in ethylene diamine tetra-acetic acid (EDTA) tubes from each participant. Genomic DNA extraction was carried out with the use of a DNA extraction kit (Qiagen, Hilden, Germany) following the manufacturer's instructions and quantified using Nanodrop 2000 Spectrophotometer (Thermo Scientific, Wilmington, DE, USA). The extracted DNA was dissolved in sterile distilled water and stored at $-20 \mathrm{C}$ before used. ALDH2 Glu504Lys and MTHFR C677T genotyping was performed used the DNA microarray chip method and direct sequencing method as previously described [23]. To verify our results, genotyping was randomly repeated in $10 \%$ of the patients with the sanger sequencing method. All the repeated experiments revealed identical results when compared with the initial genotyping.

\section{Statistical analysis}

Data were collected and all statistical analyses were performed with SPSS 19.0 (SPSS Inc., Chicago, IL, USA). Continuous variables, which were expressed as mean \pm standard deviation (SD) and analysed by $\mathrm{t}$ test or Mann-Whitney $\mathrm{U}$ test. The categorical variables were expressed as percentage and analysed by Chi-square test or Fisher's exact test. Hardy-Weinberg equilibrium (HWE) was used to assess the representativeness of the participants. Univariable logistic regression analysis was used to test the association between ACS and gene polymorphisms. To examine the association between ACS and possible confounding factors, univariate and multivariate logistic regression analysis were performed. The correlation risk was estimated by odds ratio (OR) and 95\% confidence interval $(95 \% \mathrm{CI})$. A $p$ value of $<$ 0.05 was considered statistically significant.

\section{Results}

The demographic and clinical characteristics of the study population

In this study, we analysed 860 ACS patients and 1097 control subjects. The demographic and baseline clinical characteristics of the study population were shown in Table 1 . The proportion of male, smokers, hypertension, diabetes and dyslipidemia cases were higher than those of controls and showed statistical significance $(p<0.05)$. Besides, ACS patients had elder age, higher SBP and DBP, higher serum total cholesterol (TC), LDL-c and TG levels than control subjects $(p<0.05)$. No significant differences were found with regards to the proportion of drinkers, serum high-density lipoprotein cholesterol (HDL-c), Apolipoprotein A and Apolipoprotein B levels between the two groups (all $p>0.05$ ).

\section{Genotype and allele distributions in ACS patients and controls}

Table 2 shows the allele and genotype frequencies of MTHFR C677T and ALDH2 Glu504Lys polymorphisms in ACS patients and controls. The genotype distributions of the two SNPs in the ACS patients $\left(\chi^{2}=0.119, p=0.730\right.$ and $\chi^{2}=0.254, p=0.614$, respectively) and controls $\left(\chi^{2}=0.504\right.$, $p=0.478$ and $\chi^{2}=0.126, p=0.723$, respectively) were consistent with the HWE $(p>0.05)$. The effect of the two SNPs on the risk of ACS was also performed based on dominant (normal homozygote vs. heterozygote plus mutant homozygote), recessive (normal homozygote plus heterozygote vs. mutant homozygote) and additive (normal vs. heterozygote or vs. mutant homozygote) models of inheritance. For the MTHFR C677T polymorphism, frequencies of CC, CT, and TT genotypes were $53.60 \%$ versus $55.33,39.53 \%$ versus 38.65 and $6.86 \%$ versus $6.02 \%$ in patients with ACS versus controls, respectively $(p>0.05)$. The differences in genotype frequencies between the ACS and control groups in the three genetic model were not statistically significant. 
Table 1 The demographic and clinical characteristics of the study population

\begin{tabular}{llll}
\hline Characteristics & ACS & $\begin{array}{l}\text { Controls } \\
(n=860)\end{array}$ & $\begin{array}{l}p \text { - } \\
\text { value }\end{array}$ \\
\hline Age (year) & $67.6 \pm 11.5$ & $65.7 \pm 11.7$ & $<0.001$ \\
Male $(\mathrm{n}, \%)$ & $633(73.6)$ & $709(64.6)$ & $<0.001$ \\
SBP $(\mathrm{mmHg})$ & $133.3 \pm 25.7$ & $126.1 \pm 18.7$ & $<0.001$ \\
DBP $(\mathrm{mmHg})$ & $82.6 \pm 14.91$ & $79.0 \pm 14.8$ & $<0.001$ \\
Smokers $(\mathrm{n}, \%)$ & $230(26.7)$ & $166(15.1)$ & $<0.001$ \\
Drinkers $(\mathrm{n}, \%)$ & $113(13.1)$ & $124(11.3)$ & 0.217 \\
Hypertension, $\mathrm{n}(\%)$ & $421(49.0)$ & $442(40.3)$ & $<0.001$ \\
Diabetes, $\mathrm{n}(\%)$ & $281(32.7)$ & $219(20.0)$ & $<0.001$ \\
Dyslipidemia, $\mathrm{n}(\%)$ & $266(30.9)$ & $277(25.3)$ & 0.005 \\
TG $(\mathrm{mmol} / \mathrm{L})$ & $1.74 \pm 0.80$ & $1.92 \pm 0.83$ & 0.036 \\
TC $(\mathrm{mmol} / \mathrm{L})$ & $5.06 \pm 1.35$ & $4.76 \pm 1.45$ & $<0.001$ \\
HDL-c $(\mathrm{mmol} / \mathrm{L})$ & $1.25 \pm 0.33$ & $1.26 \pm 0.41$ & 0.736 \\
LDL-c $(\mathrm{mmol} / \mathrm{L})$ & $2.90 \pm 0.98$ & $2.68 \pm 1.00$ & $<0.001$ \\
APOA (mmol/L) & $1.10 \pm 0.27$ & $1.08 \pm 0.35$ & 0.298 \\
APOB (mmol/L) & $0.86 \pm 0.29$ & $0.85 \pm 0.29$ & 0.974 \\
\hline SBP Systolic blood & & &
\end{tabular}

SBP Systolic blood pressure, DBP Diastolic blood pressure, TG Triglyceride, TC Total cholesterol, HDL-c High-density lipoprotein cholesterol, LDL-c low-density lipoprotein cholesterol, APOA Apolipoprotein A, APOB Apolipoprotein B

Another, the $\mathrm{T}$ allele frequency difference between the two groups was also not statistically significant $(p=0.362)$.

For the $A L D H 2$ Glu504Lys polymorphism, the frequencies of $A L D H 2 * 1 * 1, A L D H 2 * 1 * 2$, and $A L D H 2 * 2 * 2$ genotypes were $48.72,42.67$ and $8.6 \%$ in the ACS patients, respectively, while these were $53.33,39.11$ and $7.57 \%$ in the controls, respectively, showing no significant difference in the distribution of the $A L D H 2$ genotype between the groups. We further analysed this association in dominant model (normal homozygote $A L D H 2 * 1 * 1$ vs. heterozygote $A L D H 2 * 1 * 2$ plus mutant homozygote $A L D H 2 * 2 * 2)$. Using the wild genotype $A L D H 2 * 1 * 1$ as reference, relative risk analysis revealed a slightly increased risk for ACS in individuals with the $A L D H 2 * 1 * 2$ plus $A L D H 2 * 2 * 2$ genotypes (OR = $1.203,95 \% \mathrm{CI}=1.006-1.438, p=0.043)$. However, the differences in genotype frequencies between the ACS patients and control groups in the recessive and additive model were not statistically significant. Meanwhile, there was no significant difference between the ACS patients and control groups in the $A L D H 2 * 2$ allele frequencies $(p=0.052)$.

\section{Risk factors of ACS patients by univariate and multivariate regression}

We performed multivariate logistic regression analysis to identify the variables that independently and significantly contributed to the presence of ACS (Table 3). Multivariate logistic regression analysis after adjustment for other established risk factors: age, gender, smoking status, drinking status, hypertension, diabetes and dyslipidemia, showed that carrier of $A L D H 2 * 2$ allele was an independent risk factor for ACS (OR $=1.242,95 \% \mathrm{CI}=1.045-1.561, p=0.038)$. As regards other covariates, age, gender, smoking status, hypertension, diabetes and dyslipidemia were independent risk factors for ACS (all $p<0.05$ ). By contrast, drinking status and carrier of $\mathrm{T}$ allele in MTHFR, exerted no significant effect on ACS (all $p>0.05$ ).

\section{Discussion}

ACS is an important global public health issue and one of the leading causes of mortality rate, as well as a great economic burden for society worldwide [1]. The pathogenesis of ACS is very complex and still poorly understood. Epidemiological evidences have revealed that the manifestation of ACS are the results of the interactions between genetic and environmental risk factors [10, 12]. Discovery of genetic risk factors is of great interest in clinical practice, and will help improve the prevention of ACS and enact effective health care policies. In the present study, we for the first time investigated the association of MTHFR C677T polymorphism and ALDH2 Glu504Lys polymorphism with ACS in a Chinese Hakka population. Next we performed genotype association test with dominant, recessive, and additive models. Our results indicated that ACS patients with the mutant $A L D H 2$ (dominant model) had an increased risk of ACS $(\mathrm{OR}=1.203,95 \% \mathrm{CI}=1.006-1.438$, $p=0.043$ ). In a multivariate logistic regression model, even after adjusting for potential covariates, the association between $A L D H 2 * 2$ allele and ACS remained significant $(\mathrm{OR}=1.242,95 \% \mathrm{CI}=1.045-1.561, p=0.038)$.

MTHFR is one of the most important enzymes with a pivotal role in the Hcy metabolism [14]. Accumulating evidence suggests that there was a strong link between the MTHFR gene C677T polymorphism and plasma Hcy levels [15]. Consequently, the relatively common C677T mutation in MTHFR might be an important genetic risk factor for ischemic heart disease through its effects on Hcy metabolism $[16,18]$. The implication of the MTHFR gene in CAD pathogenesis has been extensively studied in several ethnic groups while the results were inconsistent. A meta-analysis of the risk of CAD related to the MTHFR C677T polymorphism showed that individuals with TT genotype have a significantly higher risk of CAD [30]. The study of Nakai et al. in a Japanese population has shown that the incidence of TT mutation in acute angina patients is significantly higher than the healthy population [31]. Helfenstein et al. revealed that the MTHFR TT genotype and allele frequencies in patients with MI are higher than those in healthy individuals [32]. Another meta-analysis of case-control studies found that MTHFR C677T polymorphism was associated with risk of $\mathrm{MI}$ in young and middle-aged populations, particularly among Caucasians [33]. However, there were some conflicting results. Contrary to previous literatures, 
Table 2 Genotype and allele distributions in ACS patients and controls

\begin{tabular}{|c|c|c|c|c|c|c|c|}
\hline SNP & Model & Genotype & $\operatorname{ACS}(n, \%)$ & Controls(n,\%) & OR & $95 \% \mathrm{Cl}$ & $p$-value \\
\hline \multirow[t]{10}{*}{ MTHFR C677T } & \multirow[t]{2}{*}{ Dominant } & CC & $461(53.60)$ & $607(55.33)$ & 1.000 & reference & \\
\hline & & $C T+T T$ & $399(46.40)$ & $490(44.67)$ & 1.072 & $0.896-1.283$ & 0.446 \\
\hline & \multirow[t]{2}{*}{ Recessive } & $\mathrm{CC}+\mathrm{CT}$ & 801 (93.14) & $1031(93.98)$ & 1.000 & reference & \\
\hline & & $\pi$ & $59(6.86)$ & $66(6.02)$ & 1.151 & $0.800-1.654$ & 0.449 \\
\hline & \multirow[t]{6}{*}{ Additive } & CC & $461(53.60)$ & $607(55.33)$ & 1.000 & reference & \\
\hline & & $C T$ & $340(39.53)$ & $424(38.65)$ & 1.056 & $0.876-1.273$ & 0.569 \\
\hline & & $\Pi$ & $59(6.86)$ & $66(6.02)$ & 1.177 & $0.812-1.707$ & 0.389 \\
\hline & & C allele & $1262(73.37)$ & $1638(74.66)$ & 1.000 & reference & \\
\hline & & T allele & $458(26.63)$ & $556(25.34)$ & 1.069 & $0.926-1.235$ & 0.362 \\
\hline & & HWE & $x^{2}=0.119, p=0.730$ & $x^{2}=0.504, p=0.478$ & & & \\
\hline \multirow[t]{10}{*}{ ALDH2 Glu504Lys } & \multirow[t]{2}{*}{ Dominant } & $*^{*}{ }^{* 1}$ & 419 (48.72) & $585(53.33)$ & 1.000 & reference & \\
\hline & & ${ }^{*} 1 * 2+{ }^{*} 2 * 2$ & $441(51.28)$ & $512(46.67)$ & 1.203 & $1.006-1.438$ & 0.043 \\
\hline & \multirow[t]{2}{*}{ Recessive } & $*^{*} *^{*} 1+{ }^{*} 1^{*} 2$ & $786(91.40)$ & $1014(94.43)$ & 1.000 & reference & \\
\hline & & $* 2 * 2$ & $74(8.60)$ & $83(7.57)$ & 1.150 & $0.829-1.595$ & 0.401 \\
\hline & \multirow[t]{6}{*}{ Additive } & $*^{*}{ }^{*} 1$ & 419 (48.72) & $585(53.33)$ & 1.000 & reference & \\
\hline & & $*^{*} *^{2}$ & $367(42.67)$ & $429(39.11)$ & 1.194 & $0.990-1.441$ & 0.063 \\
\hline & & $* 2 * 2$ & $74(8.60)$ & $83(7.57)$ & 1.245 & $0.888-1.745$ & 0.203 \\
\hline & & *1 allele & $1205(70.06)$ & $1599(72.88)$ & 1.000 & reference & \\
\hline & & *2 allele & $515(29.94)$ & $595(27.12)$ & 1.149 & $0.999-1.321$ & 0.052 \\
\hline & & HWE & $x^{2}=0.254, p=0.614$ & $x^{2}=0.126, p=0.723$ & & & \\
\hline
\end{tabular}

SNP Single nucleotide polymorphism, OR Odds ratio, $C I$ Confidence interval, HWE Hardy-Weinberg equilibrium

our results in the present study did not showed such a positive association between the MTHFR C677T polymorphism and elevated risk of ACS. Similar findings were also observed in ACS patients of Asian, Caucasian and African descent [34-36]. The discrepancy between the results from across several studies is unclear and may be due to differences in nutritional intake or deficiencies required for the MTHFR pathway, such as folate, pyridoxal phosphate (B6) or methylcobalamin (B12), or ethnic populations and genetic backgrounds exist [37-39].
ALDH2 is the major enzyme that eliminates exogenous and endogenous toxic aldehydes, such as acetaldehyde, 4HNE and environmental aldehydes like acrolein [40]. Up to $40 \%$ of East Asians carry a variant $A L D H 2$ with deficient catalytic activity [22]. Importantly, recent studies indicate that carriers of $A L D H 2 * 2$ mutation have an increased risk for alcoholic cirrhosis, cancer and CAD [25, 27]. Prior studies has provided evidences that $A L D H 2$ protects against myocardial ischemia/reperfusion (I/R) injury by removing toxic aldehydes such as 4-HNE in animal models of

Table 3 Univariate and multivariate logistic regression analysis for risk factors in ACS patients

\begin{tabular}{|c|c|c|c|c|c|c|}
\hline \multirow[t]{2}{*}{ Variable } & \multicolumn{3}{|c|}{ Univariate } & \multicolumn{3}{|c|}{ Multivariate } \\
\hline & $\mathrm{OR}$ & $95 \% \mathrm{Cl}$ & $p$-value & $\mathrm{OR}$ & $95 \% \mathrm{Cl}$ & $p$-value \\
\hline Age & 1.362 & $1.137-1.631$ & 0.001 & 1.514 & $1.250-1.835$ & $<0.001$ \\
\hline Gender & 1.526 & $1.255-1.856$ & $<0.001$ & 1.385 & $1.118-1.716$ & 0.003 \\
\hline Smoking & 2.048 & $1.637-2.561$ & $<0.001$ & 2.284 & $1.762-2.961$ & $<0.001$ \\
\hline Drinking & 0.751 & $0.477-1.183$ & 0.217 & 0.831 & $0.513-1.274$ & 0.229 \\
\hline Hypertension & 1.421 & $1.187-1.702$ & $<0.001$ & 1.387 & $1.147-1.676$ & 0.001 \\
\hline Diabetes & 1.946 & $1.584-2.390$ & $<0.001$ & 1.939 & $1.567-2.398$ & $<0.001$ \\
\hline Dyslipidemia & 1.326 & $1.087-1.617$ & 0.005 & 1.317 & $1.069-1.622$ & 0.010 \\
\hline MTHFR T allele carriers & 1.072 & $0.896-1.283$ & 0.446 & 1.106 & $0.933-1.358$ & 0.289 \\
\hline ALDH2 ${ }^{*} 2$ allele carriers & 1.203 & $1.006-1.438$ & 0.043 & 1.242 & $1.045-1.561$ & 0.038 \\
\hline
\end{tabular}


myocardial ischemia [28, 41]. Jo et al. suggested that genotypes carrying the mutant $A L D H 2$ allele were significantly more frequent in patients with MI than in the controls, indicating that $A L D H 2$ gene is a risk factor for MI [42]. A meta-analysis by $\mathrm{Gu}$ et al. provides strong evidence that ALDH2 Glu504Lys polymorphism may be associated with increased risk of $\mathrm{CAD}$ and $\mathrm{MI}$ in East Asians, especially among Chinese and Korean populations [21, 43]. Interestingly, in the present study, a similar result was revealed that ALDH2 mutant genotypes (*1/*2 plus *2/*2) might serve as an independent genetic risk factors for ACS in a Hakka population in southern China, which was consisted with a previous study in Han Chinese [44]. The underlying mechanism between $A L D H 2$ Glu504Lys polymorphism and risk of ACS is considered multifactorial. The genetic variation in the $A L D H 2$ gene can influence serum high-density lipoprotein-C levels and intracellular asymmetric dimethylarginine levels, subsequently increase the risk of ACS [21, 45]. The $A L D H 2$ genetic polymorphism was also significantly associated with alcohol consumption and increase blood pressure, and others has revealed a beneficial role of $A L D H 2$ against alcohol, acetaldehyde and toxic aldehydeinduced reactive oxygen species formation, and tissue injury [21, 46-48]. However, the exact mechanism still needs further verification.

It should be noted that the results of this observational study have some limitations. Firstly, the main study limitation was based upon the retrospective design of the study and patient selection biases could not be avoided. Secondly, this study is a single-center study and the sample size of the study may not be sufficiently large. To further validate the association between $A L D H 2 * 2$ variant and the risk of ACS patients, additional studies employing larger cohorts will be needed in the future.

\section{Conclusion}

The present study showed the possible clinical impact of the $A L D H 2 \% 2$ variant on ACS patients in a Hakka population in southern China. We hope our findings might help to stratify the high-risk ACS patients and implement appropriate strategies for this genetic subpopulation to ultimately guide the precision preventive procedures. However, more efforts is urgently required to confirm this hypothesis in the future.

\footnotetext{
Abbreviations

4-HNE: 4-hydroxy-2-nonenal; ACS: Acute coronary syndrome; ALDH2: Aldehyde dehydrogenase 2; APOA: Apolipoprotein A; APOB: Apolipoprotein B; CAD: Coronary artery disease; Cl: Confidence interval; DBP: Diastolic blood pressure; EDTA: Ethylene diamine tetra-acetic acid; Hcy: Homocysteine; HDL-c: High-density lipoprotein cholesterol; HWE: Hardy-Weinberg equilibrium; LDL-c: Low-density lipoprotein cholesterol; MI: Myocardial infarction; MTHFR: Methylenetetrahydro folate reductase; NSTEMI: Non-ST segment elevation myocardial infarction; OR: Odds ratio; SBP: Systolic blood pressure; SD: Standard deviation; SNP: Single nucleotide polymorphism; STEMI: ST segment elevation myocardial infarction; TC: Total cholesterol; TG: Triglycerides; UA: Unstable angina
}

\section{Acknowledgements}

The author would like to thank other colleagues whom were not listed in the authorship of Clinical Core Laboratory, Meizhou People's Hospital (Huangtang Hospital), Meizhou Hospital Affiliated to Sun Yat-sen University for their helpful comments on the manuscript.

\section{Authors' contributions}

$\mathrm{JH}$ conceived and designed the experiments; ZZ and QD recruited subjects and collected clinical data. XZ conducted the laboratory testing. ZZ and LL in helped to analyze the data. JH and ZZ prepare the manuscript. All authors have reviewed the submitted manuscript and approve the manuscript for submission.

\section{Funding}

This research was supported by the Medical Scientific Research Foundation of Guangdong Province through grant number A2017404(to Jingyuan Hou); Science and Technology Program of Meizhou through grant number 2018B024(to Jingyuan Hou); Key Scientific and Technological Project of Meizhou People's Hospital through grant number MPHKSTP-20180101(to Zhixiong Zhong); Key Scientific and Technological Project of Meizhou People's Hospital through grant number MPHKSTP-20170102(to Zhixiong Zhong).

\section{Availability of data and materials}

The datasets generated during the current study are available from the corresponding author on reasonable request.

Ethics approval and consent to participate

The ethics committee of Meizhou People's Hospital approved the protocol. All participants signed the written informed consents form.

\section{Consent for publication}

Not applicable.

\section{Competing interests}

The authors declare that they have no competing interests.

\section{Author details}

${ }^{1}$ Clinical Core Laboratory, Meizhou People's Hospital (Huangtang Hospital), Meizhou Hospital Affiliated to Sun Yat-sen University, No. 63 Huangtang Road, Meijiang District, Meizhou 514031, People's Republic of China. ${ }^{2}$ Guangdong Provincial Key Laboratory of Precision Medicine and Clinical Translational Research of Hakka Population, Meizhou 514031, People's Republic of China. ${ }^{3}$ Guangdong Provincial Engineering and Technological Research Center for Molecular Diagnostics of Cardiovascular Diseases, Meizhou 514031, People's Republic of China. ${ }^{4}$ Center for Cardiovascular Diseases, Meizhou People's Hospital (Huangtang Hospital), Meizhou Hospital Affiliated to Sun Yat-sen University, Meizhou 514031, People's Republic of China.

Received: 2 April 2019 Accepted: 2 March 2020

Published online: 11 March 2020

\section{References}

1. Sanchis-Gomar F, Perez-Quilis C, Leischik R, Lucia A. Epidemiology of coronary heart disease and acute coronary syndrome. Ann Transl Med. 2016;4(13):256.

2. Morrow DA, Cannon CP, Jesse RL, Newby LK, Ravkilde J, Storrow AB, et al. National Academy of Clinical Biochemistry Laboratory Medicine Practice Guidelines: clinical characteristics and utilization of biochemical markers in acute coronary syndromes. Circulation. 2007;115(13):e356-75.

3. Pollehn T, Brady WJ, Perron AD, Morris F. The electrocardiographic differential diagnosis of ST segment depression. Emerg Med J. 2002;19(2): 129-35.

4. Amsterdam EA, Wenger NK, Brindis RG, Casey DE Jr, Ganiats TG, Holmes DR $\mathrm{Jr}$, et al. 2014 AHA/ACC guideline for the management of patients with non-ST-elevation acute coronary syndromes: executive summary: a report of the American College of Cardiology/American Heart Association Task Force on Practice Guidelines. Circulation. 2014;130(25):2354-94.

5. Roffi M, Patrono C, Collet JP, Mueller C, Valgimigli M, Andreotti F, et al. 2015 ESC Guidelines for the management of acute coronary syndromes in 
patients presenting without persistent ST-segment elevation: task force for the management of acute coronary syndromes in patients presenting without persistent ST-segment elevation of the European Society of Cardiology (ESC). Eur Heart J. 2016;37(3):267-315.

6. Guo R, Li Y, Wen J, Li W, Xu Y. Elevated plasma level of pentraxin-3 predicts in-hospital and 30-day clinical outcomes in patients with non-ST-segment elevation myocardial infarction who have undergone percutaneous coronary intervention. Cardiology. 2014;129(3):178-88.

7. Fox KA, Dabbous OH, Goldberg RJ, Pieper KS, Eagle KA, Van de Werf F, et al. Prediction of risk of death and myocardial infarction in the six months after presentation with acute coronary syndrome: prospective multinational observational study (GRACE). BMJ. 2006;333(7578):1091.

8. Yagi H, Komukai K, Hashimoto K, Kawai M, Ogawa T, Anzawa R, et al. Difference in risk factors between acute coronary syndrome and stable angina pectoris in the Japanese: smoking as a crucial risk factor of acute coronary syndrome. J Cardiol. 2010;55(3):345-53.

9. Cheng X, Li W, Guo J, Wang Y, Gu H, Teo K, et al. Physical activity levels, sport activities, and risk of acute myocardial infarction: results of the INTERHEART study in China. Angiology. 2014;65(2):113-21.

10. Yusuf S, Hawken S, Ounpuu S, Dans T, Avezum A, Lanas F, et al. Effect of potentially modifiable risk factors associated with myocardial infarction in 52 countries (the INTERHEART study): case-control study. Lancet. 2004; 364(9438):937-52.

11. Sarwar N, Gao P, Seshasai SR, Gobin R, Kaptoge S, Di Angelantonio E, et al. Diabetes mellitus, fasting blood glucose concentration, and risk of vascular disease: a collaborative meta-analysis of 102 prospective studies. Lancet. 2010;375(9733):2215-22.

12. Deloukas P, Kanoni S, Willenborg C, Farrall M, Assimes TL, Thompson JR, et al. Large-scale association analysis identifies new risk loci for coronary artery disease. Nat Genet. 2013;45(1):25-33.

13. Nikpay M, Goel A, Won HH, Hall LM, Willenborg C, Kanoni S, et al. A comprehensive 1,000 genomes-based genome-wide association metaanalysis of coronary artery disease. Nat Genet. 2015;47(10):1121-30.

14. Kluijtmans LA, Young IS, Boreham CA, Murray L, McMaster D, McNulty H, et al. Genetic and nutritional factors contributing to hyperhomocysteinemia in young adults. Blood. 2003;101(7):2483-8.

15. Brattstrom L, Wilcken DE, Ohrvik J, Brudin L. Common methylenetetrahydrofolate reductase gene mutation leads to hyperhomocysteinemia but not to vascular disease: the result of a metaanalysis. Circulation. 1998;98(23):2520-6.

16. Kerkeni M, Addad F, Chauffert M, Myara A, Gerhardt M, Chevenne D, et al. Hyperhomocysteinaemia, methylenetetrahydrofolate reductase polymorphism and risk of coronary artery disease. Ann Clin Biochem. 2006; 43(Pt 3):200-6.

17. Tripathi R, Tewari S, Singh PK, Agarwal S. Association of homocysteine and methylene tetrahydrofolate reductase (MTHFR C677T) gene polymorphism with coronary artery disease (CAD) in the population of North India. Genet Mol Biol. 2010;33(2):224-8.

18. Clarke R, Daly L, Robinson K, Naughten E, Cahalane S, Fowler B, et al. Hyperhomocysteinemia: an independent risk factor for vascular disease. N Engl J Med. 1991;324(17):1149-55.

19. Jacques PF, Bostom AG, Williams RR, Ellison RC, Eckfeldt JH, Rosenberg $\mathbb{H}$, et al. Relation between folate status, a common mutation in methylenetetrahydrofolate reductase, and plasma homocysteine concentrations. Circulation. 1996;93(1):7-9.

20. Bosron WF, Li TK. Genetic polymorphism of human liver alcohol and aldehyde dehydrogenases, and their relationship to alcohol metabolism and alcoholism. Hepatology. 1986;6(3):502-10.

21. Guo YJ, Chen L, Bai YP, Li L, Sun J, Zhang GG, et al. The ALDH2 Glu504Lys polymorphism is associated with coronary artery disease in Han Chinese: relation with endothelial ADMA levels. Atherosclerosis. 2010;211(2):545-50.

22. Li H, Borinskaya S, Yoshimura K, Kal'ina N, Marusin A, Stepanov VA, et al. Refined geographic distribution of the oriental ALDH2*504Lys (nee 487Lys) variant. Ann Hum Genet. 2009;73(Pt 3):335-45.

23. Zhong Z, Hou J, Li B, Zhang Q, Li C, Liu Z, et al. Genetic polymorphisms of the mitochondrial aldehyde dehydrogenase $\mathrm{ALDH} 2$ gene in a large ethnic Hakka population in southern China. Med Sci Monit. 2018;24:2038-44.

24. Zhang X, Ye YL, Wang YN, Liu FF, Liu XX, Hu BL, et al. Aldehyde dehydrogenase 2 genetic variations may increase susceptibility to Parkinson's disease in Han Chinese population. Neurobiol Aging. 2015;36(9): 2660.e9-13.
25. Li R, Zhao Z, Sun M, Luo J, Xiao Y. ALDH2 gene polymorphism in different types of cancers and its clinical significance. Life Sci. 2016;147:59-66.

26. Guo JM, Liu AJ, Zang P, Dong WZ, Ying L, Wang W, et al. ALDH2 protects against stroke by clearing 4-HNE. Cell Res. 2013;23(7):915-30.

27. Chen CH, Budas GR, Churchill EN, Disatnik MH, Hurley TD, Mochly-Rosen D. Activation of aldehyde dehydrogenase-2 reduces ischemic damage to the heart. Science. 2008;321(5895):1493-5.

28. Mizuno Y, Hokimoto S, Harada E, Kinoshita K, Nakagawa K, Yoshimura M, et al. Variant Aldehyde Dehydrogenase $2\left(\mathrm{ALDH}^{*} 2\right)$ is a risk factor for coronary spasm and ST-segment elevation myocardial infarction. J Am Heart Assoc. 2016;5(5):e003247.

29. Takeuchi F, Yokota M, Yamamoto K, Nakashima E, Katsuya T, Asano H, et al. Genome-wide association study of coronary artery disease in the Japanese. Eur J Hum Genet. 2012;20(3):333-40.

30. Klerk M, Verhoef $\mathrm{P}$, Clarke R, Blom HJ, Kok FJ, Schouten EG, et al. MTHFR 677C-->T polymorphism and risk of coronary heart disease: a meta-analysis. JAMA. 2002;288(16):2023-31.

31. Nakai K, Fusazaki T, Suzuki T, Ohsawa M, Ogiu N, Kamata J, et al. Genetic polymorphism of 5,10-methylenetetrahydrofolate increases risk of myocardial infarction and is correlated to elevated levels of homocysteine in the Japanese general population. Coron Artery Dis. 2000;11(1):47-51.

32. Helfenstein T, Fonseca FA, Relvas WG, Santos AO, Dabela ML, Matheus SC, et al. Prevalence of myocardial infarction is related to hyperhomocysteinemia but not influenced by C677T methylenetetrahydrofolate reductase and A2756G methionine synthase polymorphisms in diabetic and non-diabetic subjects. Clin Chim Acta. 2005; 355(1-2):165-72.

33. Xuan C, Bai XY, Gao G, Yang Q, He GW. Association between polymorphism of methylenetetrahydrofolate reductase (MTHFR) C677T and risk of myocardial infarction: a meta-analysis for 8,140 cases and 10,522 controls. Arch Med Res. 2011;42(8):677-85

34. Anderson JL, King GJ, Thomson MJ, Todd M, Bair TL, Muhlestein JB, et al. A mutation in the methylenetetrahydrofolate reductase gene is not associated with increased risk for coronary artery disease or myocardial infarction. J Am Coll Cardiol. 1997;30(5):1206-11.

35. Hsu LA, Ko YL, Wang SM, Chang CJ, Hsu TS, Chiang CW, et al. The C677T mutation of the methylenetetrahydrofolate reductase gene is not associated with the risk of coronary artery disease or venous thrombosis among Chinese in Taiwan. Hum Hered. 2001;51(1-2):41-5.

36. Lewis SJ, Ebrahim S, Davey SG. Meta-analysis of MTHFR 677C->T polymorphism and coronary heart disease: does totality of evidence support causal role for homocysteine and preventive potential of folate? BMJ. 2005;331(7524):1053.

37. Cai C, Xiao R, Van Halm-Lutterodt N, Zhen J, Huang X, Xu Y, et al. Association of MTHFR, SLC19A1 genetic polymorphism, serum folate, vitamin B12 and Hcy status with cognitive functions in Chinese adults. Nutrients. 2016:8(10):665.

38. Gasparovic J, Raslova K, Basistova Z, Zacharova M, Wsolova L, Avdicova M, et al. Effect of C677T methylenetetrahydrofolate reductase gene polymorphism on plasma homocysteine levels in ethnic groups. Physiol Res. 2004;53(2):215-8.

39. Huang T, Tucker KL, Lee YC, Crott JW, Parnell LD, Shen J, et al. Interactions between genetic variants of folate metabolism genes and lifestyle affect plasma homocysteine concentrations in the Boston Puerto Rican population. Public Health Nutr. 2011;14(10):1805-12.

40. Chen CH, Ferreira JC, Gross ER, Mochly-Rosen D. Targeting aldehyde dehydrogenase 2: new therapeutic opportunities. Physiol Rev. 2014;94(1):1-34.

41. Sun A, Zou Y, Wang P, Xu D, Gong H, Wang S, et al. Mitochondrial aldehyde dehydrogenase 2 plays protective roles in heart failure after myocardial infarction via suppression of the cytosolic JNK/p53 pathway in mice. J Am Heart Assoc. 2014;3(5):e000779.

42. Jo SA, Kim EK, Park MH, Han C, Park HY, Jang Y, et al. A Glu487Lys polymorphism in the gene for mitochondrial aldehyde dehydrogenase 2 is associated with myocardial infarction in elderly Korean men. Clin Chim Acta. 2007;382(1-2):43-7.

43. Gu JY, Li LW. ALDH2 Glu504Lys polymorphism and susceptibility to coronary artery disease and myocardial infarction in east Asians: a metaanalysis. Arch Med Res. 2014;45(1):76-83.

44. Xu F, Chen YG, Xue L, Li RJ, Zhang H, Bian Y, et al. Role of aldehyde dehydrogenase 2 Glu504lys polymorphism in acute coronary syndrome. J Cell Mol Med. 2011;15(9):1955-62. 
45. Wada M, Daimon M, Emi M, lijima H, Sato H, Koyano S, et al. Genetic association between aldehyde dehydrogenase 2 (ALDH2) variation and high-density lipoprotein cholesterol (HDL-C) among non-drinkers in two large population samples in Japan. J Atheroscler Thromb. 2008:15(4):179-84.

46. Mukamal K, Jadhav PP, D'Agostino RB, Massaro JM, Mittleman MA, Lipinska I, et al. Alcohol consumption and hemostatic factors: analysis of the Framingham offspring cohort. Circulation. 2001;104(12):1367-73.

47. Li SY, Ren J. Cardiac overexpression of alcohol dehydrogenase exacerbates chronic ethanol ingestion-induced myocardial dysfunction and hypertrophy: role of insulin signaling and ER stress. J Mol Cell Cardiol. 2008;44(6):9921001.

48. Li SY, Li Q, Shen JJ, Dong F, Sigmon VK, Liu Y, et al. Attenuation of acetaldehyde-induced cell injury by overexpression of aldehyde dehydrogenase-2 (ALDH2) transgene in human cardiac myocytes: role of MAP kinase signaling. J Mol Cell Cardiol. 2006;40(2):283-94.

\section{Publisher's Note}

Springer Nature remains neutral with regard to jurisdictional claims in published maps and institutional affiliations.

Ready to submit your research? Choose BMC and benefit from:

- fast, convenient online submission

- thorough peer review by experienced researchers in your field

- rapid publication on acceptance

- support for research data, including large and complex data types

- gold Open Access which fosters wider collaboration and increased citations

- maximum visibility for your research: over $100 \mathrm{M}$ website views per year

At BMC, research is always in progress.

Learn more biomedcentral.com/submissions 